University of Wollongong

Research Online

Faculty of Social Sciences - Papers (Archive) Faculty of Arts, Social Sciences \& Humanities

$1-1-2019$

Reproduction and transformation of students' technology practice: The tale of two distinctive secondary student cases

Karley A. Beckman

University of Wollongong, karleymc@uow.edu.au

Sue Bennett

University of Wollongong, sbennett@uow.edu.au

Lori Lockyer

University of Wollongong, lori.lockyer@gmail.com

Follow this and additional works at: https://ro.uow.edu.au/sspapers

Part of the Education Commons, and the Social and Behavioral Sciences Commons

Research Online is the open access institutional repository for the University of Wollongong. For further information contact the UOW Library: research-pubs@uow.edu.au 


\title{
Reproduction and transformation of students' technology practice: The tale of two distinctive secondary student cases
}

\author{
Abstract \\ Disparities in the technology practices, skills and knowledge of school students still exist, despite \\ widespread investment, and use in schools. In order to understand why inequalities remain, we first need \\ a more nuanced understanding of students' technology practice, including understanding how their \\ backgrounds, circumstances and experiences shape their perceptions of and engagement with \\ technology. This paper proposes that research in the field of educational technology would benefit from a \\ sociological framing in order to highlight how and why students use technology at school and in their \\ everyday lives. The paper reports on a qualitative embedded case study of 13-16-year-old students in two \\ Australian secondary schools. In-depth case studies of two selected students illustrate the complex \\ nature of students' technology practice. Bourdieu's concepts of field, habitus and capital are used as a \\ lens through which to view and understand inequalities in students' technology practice. The findings \\ demonstrate the utility of sociological theory in educational technology research by highlighting systems \\ and structures of reproduction and transformation. Furthermore, the findings can inform an approach to \\ teaching and learning that considers students' varied experiences, knowledge, perspectives and \\ backgrounds relating to technology.
}

\section{Keywords}

tale, two, student, technology, students', transformation, reproduction, cases, practice:, distinctive, secondary

\section{Disciplines}

Education | Social and Behavioral Sciences

\section{Publication Details}

Beckman, K., Bennett, S. \& Lockyer, L. (2019). Reproduction and transformation of students' technology practice: The tale of two distinctive secondary student cases. British Journal of Educational Technology, 50 (6), 3315-3328. 
Reproduction and transformation of students' technology practice: The tale of two distinctive secondary student cases

Karley Beckman, Sue Bennett and Lori Lockyer

Address for correspondence: Karley Beckman, School of Education, University of Wollongong, Northfields Ave, NSW, 2522, Australia.

Email:karleymc@uow.edu.au

Karley Beckman is a lecturer at the University of Wollongong. Her research focuses on students' technology practices, with particular interest in exploring children and young peoples' practices with technologies across their everyday lives and educational contexts. Sue Bennett is a professor and the head of the School of Education at the University of Wollongong. Sue's current works investigate how people engage with technology in their everyday lives and in educational settings; and design thinking and learning design.

Lori Lockyer is a professor and the dean of the Graduate Research School at the University of Technology Sydney. Her research focuses on learning design and on teaching and learning with technology in school, university and professional learning environments.

\begin{abstract}
Disparities in the technology practices, skills and knowledge of school students still exist, despite widespread investment, and use in schools. In order to understand why inequalities remain, we first need a more nuanced understanding of students' technology practice, including understanding how their backgrounds, circumstances and experiences shape their perceptions of and engagement with technology. This paper proposes that research in the field of educational technology would benefit from a sociological framing in order to highlight how and why students use technology at school and in their everyday lives. The paper reports on a qualitative embedded case study of 13-16 year old students in two Australian secondary schools. In-depth case studies of two selected students illustrate the complex nature of students' technology practice. Bourdieu's concepts of field, habitus and capital are used as a lens through which to view and understand inequalities in students' technology practice. The findings demonstrate the utility of sociological theory in educational technology research by highlighting systems and structures of reproduction and transformation. Furthermore, the findings can inform an approach to teaching and learning that considers students' varied experiences, knowledge, perspectives, and backgrounds relating to technology.
\end{abstract}


Keywords sociological theory, Bourdieu's theory of practice, technology practice, school students, digital technology

\section{Structured practitioner notes}

What is already known about this topic

- Disparities in the technology practice, skills and knowledge of school students still exists, despite widespread investment and use in schools for over two decades.

- There is a growing call for educational technology research that acknowledges the social aspects of technology practice by placing technology users at the centre of investigation, rather than the technology itself.

What this paper adds

- Proposes that sociological theory can benefit educational technology research.

- The utility of sociological theory is demonstrated through application of Bourdieu's theory of practice and presentation of two distinct student case studies.

- The student case studies demonstrate the complexity of students' technology practice, with variations in students' circumstances, dispositions, perceptions and, ultimately, practices with technology.

Implications for practice and/or policy

- Teachers should consider students' varied backgrounds and perceptions of technology when designing learning experiences.

- An understanding of the social aspects, specifically the personal and contextual factors that may facilitate or hinder students' practices with technology for learning may better inform policy and practice in schools. 


\section{Introduction}

Research suggests that disparities in the technology practice, skills and knowledge of school students still exists, despite widespread investment and use in schools for over two decades (Hatlevik and Christophersen, 2013, OECD, 2010). Government policy that drives investment in school and changes in curricular stems from an underlying assumption that these technologies will "effect" change in some way, by raising student achievement or revolutionising pedagogy. However, a growing research movement proposes that through placing the individual at the centre of investigation, rather than the technology, we can understand the social and cultural aspects of technology use and inequalities in practice (Oliver, 2013).

This study extends educational technology research into secondary school students' technology practice by investigating how and why students use technology at school and in their everyday lives. Drawing on practice theory, this study asserts that technologies are social tools and their use, a social phenomena. Thus, an understanding of students' technology practice would benefit from a sociological approach in order to understand the structures, cultures, practices and relations that constitute students' technology practice in context (Oliver, 2013, Selwyn, 2012). Bourdieu's social praxeology is one example of practice theory that may be applied to educational technology research. Bourdieu's theory of practice (1990) is particularly useful, over that of other practice theories, for its ability to understand the logic of practice (the 'sens pratique' encapsulating the direction, sense, sensation and meaning the practice has to the individual) (Nicolini, 2012). His concepts provide a lens to understand the underlying structures and relations that reproduce inequalities or potentially transform practices through an understanding or 'feel for the game' (Murphy \& Costa, 2016). Thus, the examination of students' technology practice through the theoretical concepts places the individual at the centre of investigation with exploration of the systems, structures and relations of the fields they occupy to suggest potential transformative practices (Mills, 2008).

\section{Theoretical framing}

The findings reported on in this paper are part of a broader study that investigated students' practices with technologies at school and in their everyday lives. The study was guided by Bourdieu's sociological concepts of field, habitus and capital, which 
are theoretical and methodological tools with which to understand practice. Bourdieu summarises the relational nature of these concepts as "[(habitus)(capital) $]+$ field $=$ practice" (Bourdieu, 1984, p. 95). More specifically, field is a spatial metaphor referring to the social relations, systems and structures and the associated individuals who define a space (Bourdieu, 1990). As an individual moves between fields, they occupy various positions within those fields based on the congruence of their habitus and capital with that of the field. Habitus is defined as the inculcated "system of structured, structuring dispositions" of an individual (Bourdieu, 1990, p. 52). More simply, it is the way an individual acts, feels and thinks, which is shaped by their past and present experiences and circumstances (Maton, 2012). Capital refers to the symbolic and physical assets of an individual. The value of these assets is determined by the field through recognition by others (Bourdieu, 1990). Thus, the value of one's capital is not fixed, but may vary across fields. Bourdieu outlined a number of forms of capital. Of particular relevance to this study is cultural and social capital. Cultural capital relates to knowledge, skills, taste and cultural preferences, which may be embodied, objectified or institutionalised (Bourdieu, 1986). Embodied cultural capital is the internalisation of culture by an individual (which also forms part of an individuals' habitus); objectified cultural capital is the objectification of capital in material objects; and finally, institutionalised capital is the acquisition of cultural competence through formal education. Social capital relates to the social connections and the individual's ability to derive benefit from these social networks (Bourdieu, 1986). Collectively, Bourdieu's concepts allow us to understand an individual's practices by considering their experiences, circumstances and means within the social contexts in which practices occur.

The small number of educational technology studies that have adopted a Bourdieuian approach have demonstrated its utility in understanding technology practice within their social contexts within higher education settings (Costa, 2013, Czeriewicz \& Brown, 2012) and school settings (see Beckman, Apps, Bennett and Lockyer, 2018 for a detailed review of this body of research). Generally, the studies of students' practice have focused on exploring aspects such as students' homes, the influence of family experiences and circumstances and the relationship between home and school contexts in relation to technology practice. These studies have generally focused on, 
or taken up, specific elements of Bourdieu's concepts of field, habitus and more commonly, capital.

Bourdieu's concept of capital has been used to conceptualise socio-economic structures such as the influence of family background on students' technological practice. This body of research includes investigation of the influence of students' socio-economic circumstances on their technology related habitus or capital (North, Snyder and Bulfin, 2008, Robinson, 2009, Sutherland-Smith, Snyder and Angus, 2003) and familial experiences and circumstances on students' technology practice (Cranmer, 2006, Hollingworth, Mansaray, Allen and Rose, 2011). Czerniewicz and Brown (2012) present an in-depth analysis of cultural capital (embodied and objectified) through the case study of two higher education students. This case study demonstrates the acquisition of objectified cultural capital through technology devices, and the development and appropriation of embodied cultural capital through these students' experiences with technologies. Sociological theory in these studies have explored how students' knowledge and skills with particular technology practices in the school field are shaped by structures in their home fields such as family practices and value of technologies for learning.

Bourdieu's concept of field has been used to explore the relations between students' technology practice and the field in which they occur as well as the relationships between fields (Beckman, et al., 2014, Bulfin and North, 2007, Czerniewicz and Brown, 2013, Johnson, 2009). For example, in a case study of teenage technology experts Bourdieu's theory conceptualised the differences between students' formal and informal learning with technologies in the home and school fields. The findings of this study highlighted differences in the field structures across school and home fields for leisure, including extended networks of social supports and contacts available in the home field and higher levels of autonomy creating informal learning opportunities not present in their formal learning (Johnson, 2009). Another study focused on technology practice of higher education students as they manoeuvred between their everyday lives and the higher education field (Czerniewicz and Brown, 2013). This study used the concepts of habitus and field to conceptualise the variances in how technological devices and practices were valued according to field, for example, the use of mobile technologies was highly valued in everyday life fields, but 
not in higher education. The theoretical framing of these studies uncovered differences and tensions between fields of technology practice as individuals operated in different fields with implications for how we understand students' technology practice and opportunity to transfer practices, skills and knowledge across contexts. These studies demonstrate how Bourdieu's concepts can be used to explore the complexities of an individual's technology practice.

The study presented in this article adds to this small body of sociological educational technology research. Through presenting two selected student cases from the broader study, this paper provides in an in-depth exploration of students' technology practice using Bourdieu's concepts of field, habitus and capital to understand the students' technology practice for learning at school. Specifically, this paper addresses the research question: How does students' technology practice in everyday life fields shape their perceptions toward and engagement with technologies for learning?

\section{Methodology}

The study investigated secondary school students' technology practice in their everyday lives and at school. More specifically, the study conceptualised practice according to context and explored how and why the students used technologies. This paper reports findings from two student cases, selected to portray the range of technology users within the 12 cases. The example cases present a high-frequency distinctive user (Regan), and a low-frequency user (Alice).

The broader study, from which these cases were selected, involved four class cases from two schools in an Australian regional city (North and South High Schools). The class cases comprised students in Years 9 and 10 (13-16 years old) who were part of a government initiative providing students with school-issued laptops for educational use, which they could use across school and home contexts (Australian Government, 2013). Though this initiative has since concluded, 1:1 access in secondary schools is widespread through school resourcing and BYOD initiatives (Janssen and Phillipson, 2015). From the four class cases, 12 student cases were selected through purposeful maximal sampling to include variation in students' family backgrounds and their access, use and perceptions of technology. Multiple data sources were collected from each student case, including a technology diary in which students recorded the details 
of their technology practice (device/applications, details of use, location, others' involved) over a two-week period to show the range of school practices across the two-week timetabling cycle; this diary was framed by two one-on-one interviews exploring students' family backgrounds and technology practice and discussion of their practices recorded in the diary (initial and final interviews).

Bourdieu's theory of practice was used as a methodological and analytical framework in this study (see Apps, Beckman \& Bennett, in press, for a detailed description of the methodological application of the theory). The theory shaped the selection and design of data collection methods to allow for examination of technology practice with consideration of students' backgrounds and circumstances, others' technology practice and perspectives (teachers, parents, siblings, friends), past and present experiences with technologies and other contextual structures. Categorical aggregation was used to inductively code the data establishing themes and patterns, which in turn formed a coding framework that was used to analyse each data source. Following this, Bourdieu's theoretical constructs of field, habitus and capital guided a second line of analysis.

\section{Participants}

Regan, a Year 9 student from North High School, used technology frequently at school and in everyday life. She lived with her parents and two sisters. Regan used technology at school each day for learning and homework, but used technology at home predominantly for social and entertainment purposes. Regan's home use was relatively extensive compared with the other student cases, in that she used a broad range of technologies. She was keen to use technology for school related purposes, and was an avid social networker, using Twitter, YouTube, Skype and email to follow and connect with far reaching networks from around the world. Regan's parents were both professionals (ABS, 2013), her mother was a librarian and father, a marine biologist. She also lived with her older sister (studying architecture at university) and twin sister. Regan described her family using technology every day for a range of purposes including for work, study, social and leisure. Regan had access to a number of technologies including her school-issued laptop, a family shared laptop and desktops computers, access to the Internet at home, an iPod Touch, mobile phone, digital cameras and games consoles. 
Alice, a Year 10 student from South High School, lived with her parents and two sisters. She used technology infrequently at school and home. She preferred to write in her notebook at school and only took her school-issued laptop when required under teacher instruction. Alice's predominant use of technology was for learning, and while she had access to a laptop at home, she preferred to use the school-issued laptop. She had little interest in using technology for entertainment or socialising, preferring to communicate with her friends face-to-face. She perceived technology largely as a struggle: she had believed from an early age that technology was not for her and that it was difficult to use. Alice lived with her mother (casual school office assistant) and father (casual plumber), as well as an older (works at a theme park) and younger sister. Alice's family were characterised as working class based on her parent's occupations (ABS, 2013). She described that her mother and sisters used technology for social purposes predominantly using Facebook, while her father didn't use technologies. Alice had access to fewer technologies including her school-issued laptop, access to the Internet at home and a mobile phone and family shared laptop that she seldom used.

The two government schools, North High School (608 students) and South High School (1198 students), were in a regional city area in Australia. Census data of the two regions demonstrate that the northern area was characterised by a more professional work force with higher incomes, while the southern area was predominantly working class with lower incomes and fewer households connected to the internet (ABS, 2011). Students in both schools had access to comparable technologies with both schools being part of a government initiative that provided all secondary school students with a laptop for educational use.

These two student cases were distinctive and not representative of the larger cohort of participants, but serve to demonstrate how technology practice outside of school shapes students' perceptions towards and engagement with technology for learning. Table 1 provides an overview of Regan and Alice's access to technologies and characteristics of their home fields, demonstrating the differences in circumstances and access, which will be discussed in more detail below. 
Table 1 Overview of student cases and characteristics of home fields

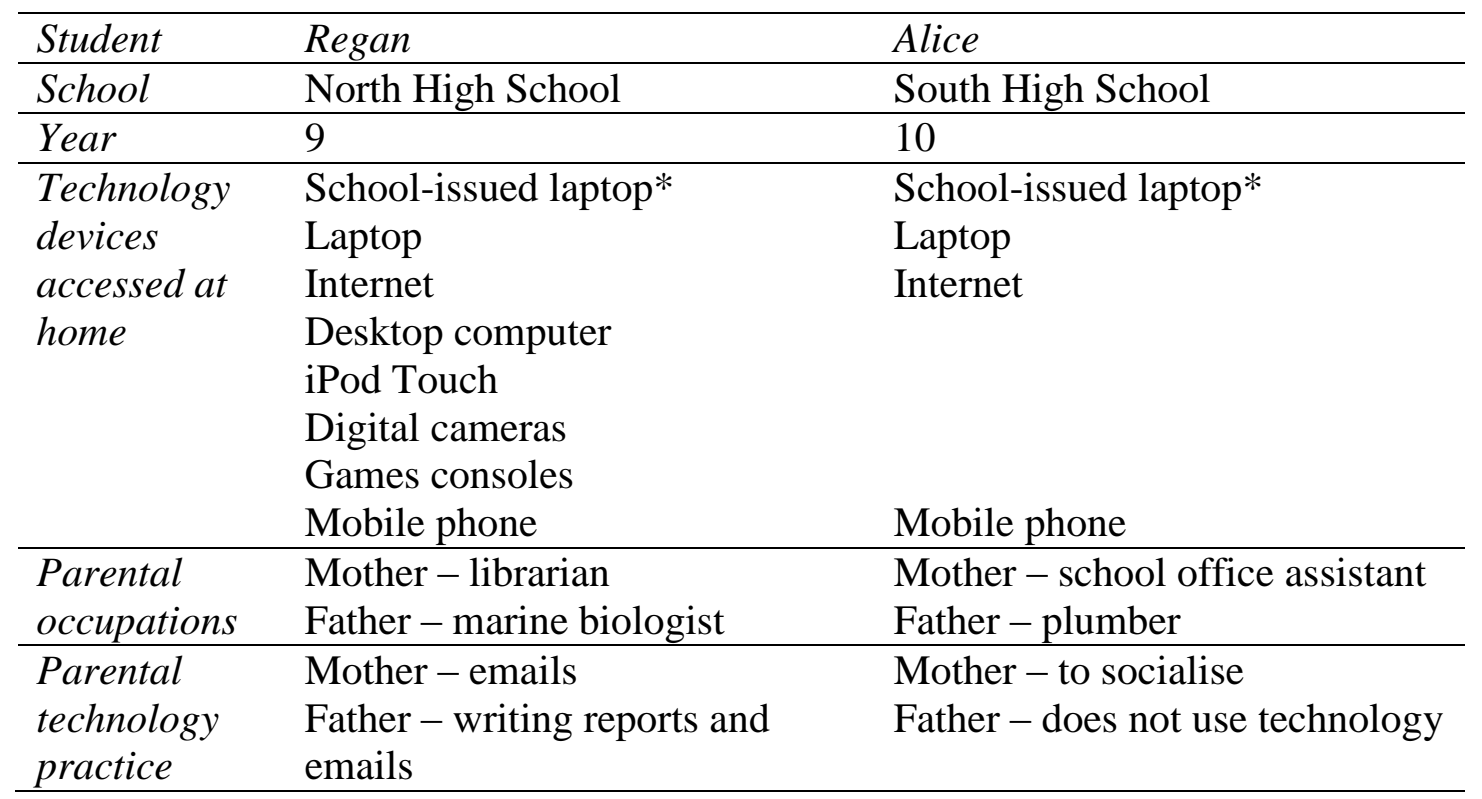

\section{Findings}

Fields of technology practice

In this study exploration of the fields of technology practice included the objective field structures including the technology resources available and accessible, location and distribution of devices; as well as embodied field structures such as rules about technology use, position in the field and culture of technology use. The findings of this study indicated four predominant fields of technology practice: the field of home educational technology practices, everyday practices at home (leisure and socialising), educational technology practices at school and everyday technology practices at school.

\section{Home fields}

Students had access to a varying range of technological resources in their homes that shaped the technology practice available to them (Table 1). Both students had access to a computer with internet access and was able to use it in their preferred location within the home. In the initial interview, Regan explained she preferred to use technologies that allowed her to be mobile, such as a laptop, an iPod Touch and a mobile phone so she could use technology in various locations around the home. Alice preferred privacy, using her school-issued laptop in her bedroom. 
Overall, the students were generally able to use technology at home when and where they preferred. Both had their own school-issued laptop and access to other devices. Although the distribution of devices among family members meant that Alice was generally limited to the use of her school-issued laptop and mobile phone. While, Regan had access to a broader range of devices that she used according to her purpose. For example, if she was completing schoolwork started at school she would use her school-issued laptop, other schoolwork was completed on her desktop computer or laptop; while she used her iPod Touch predominantly for socialising purposes. Alice preferred using the school issued laptop as she didn't need to share it with other family members and she described it as easier to use because she could easily access relevant bookmarks she used for schoolwork. Both girls described a range of practices at home. Table 2 presents a summary of all technologies used by the students according to the field and frequency of use based on the interviews and technology diaries. During the interviews the students did not describe any limitations placed on these practices by their parents.

Table 2 Overview of technology practice in home fields

\begin{tabular}{|c|c|c|}
\hline Field & Regan & Alice \\
\hline $\begin{array}{l}\text { Everyday } \\
\text { practices at } \\
\text { home }\end{array}$ & $\begin{array}{l}\text { Every day: Twitter, Instagram } \\
\text { Most days: email, text } \\
\text { messaging, watching YouTube, } \\
\text { downloading and watching } \\
\text { movies, interest driven internet } \\
\text { browsing } \\
\text { Sometimes/rarely: Skype, } \\
\text { internet shopping }\end{array}$ & $\begin{array}{l}\text { Every day: } \mathrm{n} / \mathrm{a} \\
\text { Most days: Facebook } \\
\text { Sometimes/rarely: plays games } \\
\text { online }\end{array}$ \\
\hline $\begin{array}{l}\text { School } \\
\text { related } \\
\text { practices at } \\
\text { home }\end{array}$ & $\begin{array}{l}\text { Every day: } \mathrm{n} / \mathrm{a} \\
\text { Most days: online inquiry and } \\
\text { word processing for homework } \\
\text { Sometimes/rarely: } \mathrm{n} / \mathrm{a}\end{array}$ & $\begin{array}{l}\text { Every day: n/a } \\
\text { Most days: online inquiry and } \\
\text { word processing for homework } \\
\text { Sometimes/rarely: watches } \\
\text { educational videos online }\end{array}$ \\
\hline
\end{tabular}

School fields

Both students used their school-issued laptops at school for a narrower range of practices compared with their uses in home fields. Table 3 provides a summary of technology practices at school as described in the interviews and technology diaries. Neither student reported using a mobile device while at school in line with the school 
rules. Therefore, the two students used their school-issued laptops predominantly for classwork and occasionally to play a game during a free period or free time.

Table 3 Overview of technology practices in school fields

\begin{tabular}{lll}
\hline Field & Regan & Alice \\
\hline Everyday & Every day: n/a & Every day: n/a \\
practices at & Most days: play non-educational & Most days: n/a \\
school & games & Sometimes/rarely: play non- \\
& Sometimes/rarely: n/a & educational games \\
\hline School & Every day: writing notes using & Every day: n/a \\
related & OneNote & Most days: Edmodo (LMS), \\
practices at & Most days: word processing, & online inquiry \\
school & online inquiry & Sometimes/rarely: creating a \\
& Sometimes/rarely: watch & PowerPoint, watch educational \\
& educational videos & videos \\
\hline
\end{tabular}

The nature of students' technology use at school was more prescriptive than their everyday practices. In the technology diary, Alice recorded that all uses of her laptop were under teacher direction, as were most of Regan's recorded school uses of technology $(89 \%)$. These findings suggest that there is a difference in the culture of technology use between their everyday technology practices, where students were generally more autonomous, and school technology practices, specifically in the school field, where technology use was more prescribed.

Both students used their school-issued laptops at school, although they had different perspectives on its use for learning. Regan was an enthusiastic technology users and used her laptop in almost every class, as detailed in the technology diary. Alice preferred to complete her work in a book. She explained, "I don't bring [my laptop] extremely often to school. When I bring it, I'll get it out when I need it or when I'm told to [by the teacher]" (Initial interview).

\section{Habitus}

In this study, students' habitus was explored during the interviews through their family backgrounds, dispositions towards technology use and past and present experiences with technologies.

Family background 
Students' family backgrounds, including family uses of technology at home, provide insights into the structuring experiences in which students were involved. These experiences influence the ways students act, feel and think, and thus the degree to which they perceive technology practices as possible, probable or profitable.

In Regan's home, all members of the family used technology, "pretty much every day" (Initial interview). Her parents, both professionals, used technology for email and to write reports for work, and her sisters used technology for school and university study, as well as for socialising and leisure. Regan's practices with technology suggest that her family circumstances and experiences shaped her positive and receptive disposition toward technologies (social capital and embodied cultural capital). Alice's parents, a casual office assistant and casual plumber, both working class occupations, did not use computers at home. She wasn't aware of her sisters' practices other than their uses of their mobile phones. This suggests that Alice observed fewer uses of technology in her home and thus had a more narrow range of technology experiences, shaping her reluctant and apprehensive disposition.

\section{Dispositions towards technology}

The two students had varied dispositions toward the use of technology. Outside of school, Regan was inclined to spend hours communicating with social networks, using Twitter, YouTube, Skype and email. While Alice preferred to use the home telephone to communicate with her friends.

For Regan, social and entertainment activities dominated her use of technology at home. Conversely, Alice's main use of technology at home was for learning, where she would complete homework and assignments when required, but mostly used technology to research concepts she had not sufficiently understood at school.

There was evidence that students' use of technologies in their everyday lives structured their dispositions towards the use of technology at school. Regan's frequent use of technologies in her everyday life seemed to influence her acceptance of and positive disposition towards technology use for learning. She expressed her positive attitude toward the school's interactive whiteboards, "it's just more interesting to use it and I can engage in the lessons more" and stated that she would "prefer to use 
[laptops] more" at school (Initial interview). While Alice's preference not to use technology at home was also observed in her perceptions of technology use at school. For example, she preferred not to type her school notes on the laptop and did not value interactive technologies for learning. For example, Alice recalled, "Some people got to go up and use [the interactive whiteboard] but I didn't because I didn't want to and I didn't find the point" (Initial interview).

Bourdieu outlined that one's history is internalised and carried with the individual across fields (1990). In light of this, these findings demonstrate how students' habitus, developed within the home field through shared culture and socialisation to particular technologies and uses, may in turn shape their perceptions and use of technology at school. More specifically, these dispositions - specifically, the value Regan placed on technologies for socialising and Alice's tendency not to use technology - may be influenced by experiences and circumstances outside school (family backgrounds and past and present experiences with technology).

Past and present experiences

The participants' first technology experiences seemed to have had an enduring influence on their current practices. In the initial interview, students recalled when and how they first used computers. In both cases, most technology related learning experiences were at primary school and/or influenced by family. Regan first used a computer with her older sister to play games and use a paint application. Regan recalled watching her sister use technology, which prompted her to try. Alice explained the challenges she experienced getting access to the family computer, "we had a desktop computer when I was young and I remember using that for games...that was the only computer, so I didn't get to use it a lot" (Initial interview). She explained this computer was shared among her sisters and they were more persistent in their use of this computer. These first experiences for each participant were sustaining, influencing their current habitus. Regan's family continued to influence her practices to use technology for a range of educational, leisure and social purposes, and Alice's preference not to use technology may have been influenced by her limited experiences. 
Both students described rarely learning new technologies at high school. They explained that teachers "just assume[d]" they had technological skills and knowledge (Alice, Initial interview). For Alice, this assumption was unfounded, as she was reluctant to use technology and had limited home experiences (habitus) or supports (social capital) to draw on. For example, Alice had a laptop at home, yet preferred to use her school laptop to access educational online resources. She described her difficulties in accessing the online resources through the school intranet on her home laptop: "I could probably do that with my home laptop but it's harder" (Initial interview).

\section{Capital}

In this study, students' capital was evidenced in their access to and use of technologies (objectified cultural capital), socialisation into technology use through experiences with teachers, family and friends and time spent developing skills and knowledge (embodied cultural capital), and in their social connections and supports for their use of technologies (social capital).

The objectified cultural capital of Regan and Alice was quite different. Regan had access to and experience with a range of technologies for a range of purposes in her home. While Alice had access to fewer technologies. But this lack of access was not necessarily a direct result of the family economic capital, but was also evidence of Alice disposition towards technology (habitus) and embodied cultural capital. Alice described that her sisters had more expensive mobile phones, but that she had chosen a cheaper "\$20 one" because "[she] wouldn't have use for it" (final interview). She stated, "I don't need such a high-tech thing. I would prefer money spent on something else" (final interview). These variations in objectified cultural capital in turn shaped the opportunities to develop embodied cultural capital.

Students' embodied cultural capital was acquired through the development of technological knowledge, skills and tastes through experiences and socialisation into technology practices through interactions with others. In the home fields, the technology practices of parents, siblings and friends influenced students' practices. For example, in the interviews Regan described a range of technological uses at home by her family for work, education, socialising and entertainment, which were used 
frequently. For Regan, this shared experience of familial habitus may have provided embodied cultural capital, through the acquisition of technological knowledge, skills and preferences, some of which had currency in the school field. While Alice's embodied cultural capital acquired in the home fields was more limited where she had fewer opportunities to experience and learn technological skills and knowledge or networks of support. Alice described in the interviews that her parents rarely used technologies. Alice's limited embodied cultural capital was further evidenced in her preference not to use technology for learning (forming part of her habitus) and the difficulties she experienced with using technologies. These findings demonstrate how cultural capital may shape a students' capacity to deploy certain skills and knowledge to engage with technologies in the school field.

Within the school field the students reported minimal opportunities at school for formal learning of technology related skills and knowledge. These formal education experiences are examples of institutionalised cultural capital. For Alice, school was her main field of socialisation into technology practices. Alice described one learning experience at school that positively shaped her cultural capital, where she described learning to access online educational videos. Learning to access educational videos at school provided Alice with cultural capital, as she reported improved learning outcomes, thus shaping her perceptions of technology practices that are possible and profitable. She valued this learning experience at school, and this in turn led to her watching educational videos at home to review concepts learnt at school. This was a significant learning experience for Alice, which she valued highly. Conversely, Regan believed that she could learn any new program, and thus taught herself by investing time in learning technologies outside of school, which further developed her embodied cultural capital. Thus, Regan was able to draw on her cultural capital acquired in home fields to engage with technologies at school.

Students' technological social capital was diverse, with each student having different networks of contacts that supported their use of technology. Regan was an active social networker. Regan used online networks to access social capital not attainable through her local networks. She had international pen friends via email and Skype, and subscribed to international YouTube channels and Twitter personalities, “...like if they're from England...maybe they've gone to university...or they just make videos 
about what's happened in the week and just weird stuff like that" (Final interview). Regan's online networks provided opportunities to capitalise from connectivity by engaging with networks that provided her with news, new ideas, inspirations and aspirations, as well as opportunities to develop technological skills, knowledge and tastes (embodied cultural capital). These experiences developed Regan's social capital generally and exposed her to a culture of online creating and sharing technological practices. Alice did not use or create online networks, only occasionally looking at Facebook. Alice had one social contact, a school friend, with whom she developed her technology skills and knowledge. Alice frequently visited her friend's house on weekends, where they used a range of technologies, including video games and social networking. These experiences at her friend's home exposed Alice to technologies and practices that she may not have otherwise accessed in other fields.

These findings highlight the magnifying nature of social capital on other forms of cultural capital. For Regan, her far-reaching networks of technological contacts and support, through her family and online, may amplify her embodied cultural capital through time invested in use and socialisation into broader technology uses. Though Alice had some networks of support via school and a friend, the limited scale of her network compared to Regan resulted in a more limited exposure to technologies and was perpetuated by her limited access to and desire to acquire technologies (objectified cultural capital).

\section{Discussion}

These cases demonstrate the complexity of students' technology practices, with variations in students' circumstances, dispositions, perceptions and, ultimately, practices with technology. This paper now considers the practical implications of technology use in formal education through exploring students' backgrounds and perceptions of technology and the transformative potential of particular technology experiences as conceptualised through the theory of practice (Bourdieu, 1990). However, it should be acknowledged that the cases presented in this paper are not representative of students' technology practices in other contexts. Instead, these case studies serve to demonstrate the variation of practices within the broader sample of this study. The self-reported nature of the data also depicts a subjective account of 
students' fields and practices, and thus limits the researcher's ability to subjectively analyse fields.

In this paper, we have used Bourdieu's concepts to demonstrate how an individual's circumstances, family background and past and present experiences can structure their habitus and capital, and thus their practices. While research investigating students' backgrounds in relation to their education may be familiar, few studies have used Bourdieu's sociology to explore aspects of school students' technology practices in this way (North, Snyder, and Bulfin 2008; Robinson 2009; Johnson 2009; Kapitzke 2000; Taylor 2005). In the two cases presented in this paper, students' family backgrounds provided them with skills, knowledge, tastes and socialisation into technology, shaping their ability to distinguish and deploy particular uses of technology in various fields (cultural capital), which likely influenced their habitus and ultimately their practices with technology for learning. From the cases, Regan shared experiences with a range of agents of socialisation (social capital) into technology use, including her parents, siblings and online networks; all of these experiences contributed to her embodied cultural capital and were magnified by her social capital.

Some experiences are more profitable than others, as capital is only of value when recognised by the field (Bourdieu, 1990). For example, Alice described experiences with her friend playing games and learned about using educational videos at school with limited embodied cultural capital from her working-class family that was of value in the formal education field. While both experiences are examples of embodied cultural capital through improvement in technological skills and knowledge, only the latter has currency in the school field. This finding is consistent with a quantitative study of students' technology related cultural capital, suggesting a correlation with parents' professions (Tondeur, Cooper and Newhouse, 2010). Parents' professions may be an indicator of the technology related attitudes, technology use and skills and knowledge within the home, with the professional circumstances of the parents shaping children's skills, knowledge and tastes in the use of technology and alignment with that of formal education (Tondeur, Cooper and Newhouse, 2010). 
It is also important to note that habitus is not static, but continuously structured and restructured through one's experiences (Bourdieu, 1990). Therefore, present and future experiences with technology at school have the potential to restructure students' habitus - their perceptions of technology, and what is possible and profitable. Thus, teachers may contribute to students' cultural capital, being agents for socialisation into technology practices and support for students (social capital), and in turn potentially shaping their habitus. A recent study detailed the transformative influence of teachers on students' technology practices (Pullen, 2015). The study demonstrated that teachers' use of presentation technology tools and teaching about the use of these technologies shaped students' development of their skills and knowledge and use of the technology outside of school. In this study, Alice's experience of learning to access educational videos online at school is one example of the transformative potential of teachers and made possible through access to her school-issued laptop (objectified cultural capital). The findings suggest that her cultural capital may have shaped her habitus, as Alice described she had continued this practice at home, transforming from a non-user of technology, to a disposition toward using technology for learning at home.

Unfortunately, the findings of this study suggest that this kind of transformative experience in schools was rare, with the two students reporting mostly basic and prescriptive uses of technology at school. This is of concern, as such technology experiences do not consider students' varied habitus and capital, and thus may not align with students' learning needs or dispositions towards technology. Moreover, students' current technology practices in school suggest a lost opportunity to build cultural capital that reaps benefits for both school and home practices. While differences between school and home uses of technologies have been well documented, considering the varied structures in these fields may provide an avenue for better informing teaching practice. More specifically, an understanding of the field structures that shape technology practices may provide opportunities to better inform how technologies are used in school; for example, providing opportunities for students to make decisions about their use of technologies and providing support for students in the use of technologies that may be different from their experiences in their everyday lives. 
Bourdieu's concept of habitus provides valuable insights into students' perceptions of technologies and how these shape their practice. For example, Alice valued the use of educational videos, including extending her learning at home. The findings suggest that Alice valued this use as she profited academically (embodied cultural capital) from these practices; however, for many other uses of technology at school, Alice did not perceive the possible capital that could be gained. She had believed from an early age that technology was not for her and that it was difficult to use. This shows how habitus can restrict individuals' perceptions of what practices are either possible or unthinkable based on their social class background (Mills, 2008). Though this study did not measure students' socio-economic status, students' access to technologies, parental occupations and technology practices provide some indication of factors relating to socio-economic status. For example, Alice's family had low access to and use of technologies in the home, and her parents both engaged in working class occupations, associated with low socio-economic status. Similar studies have demonstrated patterns between low socio-economic status, negative student perception and limited resources that influenced students' modest engagement with technologies (Heemskerk, Volman, Admiraal and Ten Dam, 2012, Vekiri, 2010). This finding advances understanding of the influence of students' perceptions on their practices.

An understanding of students' backgrounds, experiences with and perceptions of technologies, conceptualised through a Bourdieuian sociology, provides potential for strategic use by schools to address student inequalities (Czerniewicz and Brown, 2013). A growing body of research demonstrates that young people's skills and knowledge with technology is more diverse and with relatively few students demonstrating high levels of digital literacy related to educational uses of technology (Corrin, Apps, Beckman, Bennett, 2018). This is of increasing importance considering the increased prominence of digital literacy and technologies in curriculums worldwide. The two cases presented highlight some personal and contextual factors that may facilitate or hinder students' practices with technology at school for learning. The reproductive nature of students' habitus was demonstrated in this study through students' practices conforming to their perceptions of and past experiences with technology. Conversely, we may also consider the transformative aspects of habitus 
and capital (Czerniewicz \& Brown, 2012, McNamara Horvat and Davis, 2010, Mills, 2008). A consideration of students' varied habitus and capital offers a transformative potential for schools to provide students with knowledge and learning experiences that broaden their perceptions of practices with technology, and thus to bridge student inequalities with technology practices for learning and expand all students' technology habitus and capital.

\section{Conclusion}

This study investigated students' practices with technologies at school and in their everyday lives. We have presented two in-depth case studies through the lens of Bourdieu's sociological theory to present a holistic understanding of students' practices that considered the influence of their backgrounds and sociocultural contexts. The findings add to the growing body of literature that acknowledges the complex nature of students' technology practices. Moreover, the lens of Bourdieu's concepts highlighted the social nature of technologies, where students' practices were shaped by and inextricably linked to the contexts in which they occurred. The descriptions yielded from the two case studies demonstrate the value of sociological theory in educational technology research in providing deeper understanding with the potential to address student inequalities. 


\section{Statements on open data, ethics and conflicts of interest}

Our data are not open to public and there are no conflicts of interest. We confirm that all the research meets the ethical guidelines, including adherence to the legal requirements of the study country.

\section{References}

Apps, T., Beckman, K., \& Bennett, S. (in press). Engaging with Bourdieu's theory of practice: An empirical tool for exploring inequality in school students' technology practice, Technology, Pedagogy \& Education.

Australian Bureau of Statistics [ABS]. (2011). 2011 census of population and housing: Basic community profile - Australia. Retrieved June, 2014, from http://www.abs.gov.au

Australian Bureau of Statistics [ABS]. (2013). Australian and New Zealand standard classification of occupations. Retrieved June, 2014, from http://www.abs.gov.au/AUSSTATS/abs@.nsf/DirClassManualsbyTopic/4AF1 38F6DB4FFD4BCA2571E200096BAD?OpenDocument

Australian Government. (2013). DER mid-program review: assessing progress of the $D E R$ and potential future directions. Final report. Retrieved from https://docs.education.gov.au/system/files/doc/other/digital_education_revolut ion_program_review.pdf

Beckman, K., Apps, T., Bennett, S. \& Lockyer, L. (2018). Conceptualising technology practice in education using Bourdieu's sociology, Learning, Media and Technology, 43, 197-210.

Beckman, K., Bennett, S., \& Lockyer, L. (2014). Understanding students' use and value of technology for learning. Learning, Media and Technology, 39, 346367.

Bourdieu, P. (1984). Distinction. London: Routledge.

Bourdieu, P. (1986a). The forms of capital. In Richardson, J. (Ed., Handbook of theory and research for the sociology of education. (pp. 241-256). Connecticut, Greenwood Press.

Bourdieu, P. (1986b). The production of belief: Contribution to an economy of symbolic goods. In Collins, R. E., Curran, J., Garnham, N., Scannell, P., Schlesinger, P. \& Sparks, C. (Eds.), Media, culture \& society: a critical reader. London, Sage.

Bourdieu, P. (1990). The logic of practice. Cambridge: Polity.

Bulfin, S., \& North, S. (2007). Negotiating Digital Literacy Practices Across School and Home: Case Studies of Young People in Australia. Language and Education, 21, 247-263.

Corrin, L., Apps, T., Beckman, K., \& Bennett, S. (2018). Myth of the Digital Native and What It Means for Higher Education. In A. Attrill-Smith, C. Fullwood, M. Keep, \& D. J. Kuss (Eds.), The Oxford Handbook of Cyberpsychology (p. 19). Oxford University Press.

Costa, C. (2013). The participatory web in the context of academic research: Landscapes of change and conflicts. Doctoral dissertation, University of Salford.

Cranmer, S. (2006). Children and young people's uses of the internet for homework. Learning, Media and Technology 31, 301-315. 
Czerniewicz, L., \& Brown, C. (2012). Objectified Cultural Capital and the Tale of Two Students. In L. Dirckinck-Holmfeld, V. Hodgson, \& D. McConnell (Eds.), Exploring the Thoery, Pedagogy and Practice of Networked Learning. New York, NY: Springer.

Czerniewicz, L. \& Brown, C. (2013). The habitus of digital "strangers" in higher education. British Journal of Educational Technology 44, 44-53.

Hatlevik, O. E. \& Christophersen, K.-A. (2013). Digital competence at the beginning of upper secondary school: Identifying factors explaining digital inclusion. Computers \& Education 63, 240-247.

Heemskerk, I., Volman, M., Admiraal, W. \& Ten Dam, G. (2012). Inclusiveness of ICT in secondary education: Students appreciation of ICT tools. International Journal of Inclusive Education 16, 155-170.

Hollingworth, S., Mansaray, A., Allen, K. \& Rose, A. (2011). Parents' perspectives on technology and children's learning in the home: Social class and the role of habitus. Journal of Computer Assisted Learning 27, 347-360.

Janssen, K. \& Phillipson, S. (2015). Are We Ready for BYOD? An Analysis of the Implementation and Communication of BYOD Programs in Victorian Schools, Australian Educational Computing, 30.

Johnson, N. F. (2009). Cyber-relations in the field of home computer use for leisure: Bourdieu and teenage technological experts. E-Learning 6, 187-197.

Kapitzke, C. (2000). Information Technology as Cultural Capital: Shifting the Boundaries of Power, Education and Information Technologies 5, 49-62.

Maton, K. (2012). Habitus. In Grenfell, M. (Ed., Pierre Bourdieu: Key concepts. (pp. 48-64). Second edn. London, Acumen.

McNamara Horvat, E., \& Davis. J.E. (2011). Schools as Sites for Transformation: Exploring the Contribution of Habitus, Youth \& Society 43, 142-170.

Mills, C. (2008). Reproduction and transformation of inequalities in schooling: The transformative potential of the theoretical constructs of Bourdieu. British Journal of Sociology of Education 29, 79-89.

Murphy, M., \& Costa, C. (2016). Theory As Method in Research : On Bourdieu, Social Theory and Education. Abingdon, Oxon: Routledge.

Nicolini, D. (2012). Practice Theory, Work, and Organization: An Introduction. OUP Oxford.

North, S., Snyder, I. \& Bulfin, S. (2008). Digital tastes: Social class and young people's technology use. Information, Communication \& Society 11, 895-911.

Oliver, M. (2013). Learning technology: Theorising the tools we study. British Journal of Educational Technology 44, 31-43.

Organisation for Economic Co-operation and Development [OECD]. (2010). Are the new millennium learners making the grade? Technology use and educational performance in PISA. Educational Research and Innovation. Retrieved from http://www.oecd.org/edu/ceri/educationalresearchandinnovationarethenewmill enniumlearnersmakingthegradetechnologyuseandeducationalperformanceinpis a2006.htm

Pullen, D. (2015). The influence of the home learning environment on middle school students' use of ICT at school. Australian Educational Computing 30.

Robinson, L. (2009). A taste for the necessary. Information, Communication \& Society 12, 488-507.

Selwyn, N. (2012). Making sense of young people, education and digital technology: The role of sociological theory. Oxford Review of Education 38, 81-96. 
Sutherland-Smith, W., Snyder, I. \& Angus, L. (2003). The digital divide: Differences in computer use between home and school in low socio-economic households. Educational Studies in Language and Literature 3, 5-19.

Taylor, A. (2005). Finding the Future That Fits, Gender and Education, 17, 165-187.

Tondeur, J., Cooper, M. \& Newhouse, C. (2010). From ICT coordination to ICT integration: A longitudinal case study. Journal of Computer Assisted Learning 26, 296-306.

Vekiri, I. (2010). Socioeconomic differences in elementary students' ICT beliefs and out-of-school experiences. Computers \& Education 54, 941-950. 